\title{
Involvement of Endothelium-Derived Factors in Controlling the Active Tone of Smooth Muscle in Aorta from Hypertensive Rats
}

\author{
Fumiko Sekiguchi, Kyoko Matsuda, Keiichi Shimamura*, \\ Kiyoko TAKeuchI and Satoru SunANo \\ Faculty of Pharmaceutical Sciences, Kinki University, 1-3-4 Kowakae, \\ Higashi-osaka 577-8502 and *Research Institute of Hypertension, Kinki \\ University, 377-2 Ohono-higashi, Osaka-sayama 589-8511, Japan
}

\begin{abstract}
Control of the active tone by endothelium in aortae from various strains of spontaneously hypertensive rats was studied. The active tone was negligibly observed in endotheliumintact preparation. The application of $\mathrm{N}^{\mathrm{G}}$-nitro-L-arginine $\left(\mathrm{L}-\mathrm{NNA}, 10^{-4} \mathrm{M}\right)$ induced slowly developed active tone in the preparations from hypertensive rats but no active tone was induced in the preparation from normotensive Wistar Kyoto rats (WKY). The developed tension was stronger in preparations from rats with higher blood pressure as observed in endothelium-denuded preparations. The developed active tone in the presence of $\mathrm{L}-$ NNA was greater than that observed in endothelium-denuded preparations. The active tone was abolished by the removal of extracellular $\mathrm{Ca}^{2+}$ or by the application of $\mathrm{Ca}-$ antagonists. L-arginine counteracted the effects of L-NNA and depressed the developed active tone in the presence of the latter drug. The application of indomethacin $\left(10^{-5} \mathrm{M}\right)$ depressed the active tone of the preparations from SHRSP by $25.5 \pm 5.2 \%$. Increasing extracellular $\mathrm{K}^{+}$concentration or application of tetraethylammonium (TEA) could not be used to observe the effect of endothelium-derived factors on the active tone, because of their strong contractile effect. Simultaneous application of apamin and charybdotoxin induced an elevation of tension which was often associated with spontaneous tension oscillation.

It is concluded that the active tone, which is smooth muscle origin, is depressed by endothelium-derived nitric oxide (NO) strongly and potentiated by a product of arachidonic acid cascade through cyclooxygenase pathway. The involvement of endothelium-derived hyperpolarizing factor (EDHF) in the depressing effect of endothelium is thought to be small.
\end{abstract}

Key words : active tone, aorta, SHR, endothelium-derived factors

\section{Introduction}

Smooth muscle of aorta has been known to be quiescent muscle which has no spontaneous contraction (active tone). In the spontaneously hypertensive rats, however, it has been known

Correspondence to: Fumiko Sekiguchi, Faculty of Pharmaceutical Sciences, Kinki University, 3-4-1

Kowakae, Higashi-osaka, Osaka 577-8502, Japan.

Phone: +81-6-6721-2332; ext : 3827; Fax : +81-6-6730-1394 ; E-mail : fumiko@ phar.kindai.ac.jp 
that the aortic smooth muscle exhibits the active tone (Sada et al., 1989; Fitzpatrick and Szentivanyi, 1980 ; Lindner and Heinle, 1987 ; Noon et al., 1978; Sunano et al., 1992 ; Sunano and Shimamura, 1991; Sasaki et al., 1993; Sunano et al., 1996). We have observed using various strains of spontaneously hypertensive rats that the amplitude of the active tone of aorta became greater as the blood pressure of the rats increased (Sasaki et al., 1993 ; Sunano and Shimamura, 1991; Sunano et al.,1996). It has been established that the active tone of aortic smooth muscle is sensitive to extracellular $\mathrm{Ca}^{2+}$ and is thought to be induced by influx of $\mathrm{Ca}^{2+}$ through voltage-dependent $\mathrm{Ca}^{2+}$ channels (Sasaki et al., 1993 ; Sada et al., 1989 ; Fitzpatrick and Szentivanyi, 1980 ; Noon et al., 1978; Sunano et al., 1996).

The active tone is depressed by the presence of intact endothelium (Sunano et al., 1996; Sunano et al., 1991 ; Sunano and Shimamura, 1991). The depression may be brought about by the spontaneous release of endothelium-derived relaxing factor (EDRF), which has been identified as nitric oxide (NO) (see Moncada et al., 1989), and/or endothelium-derived hyperpolarizing factor (EDHF) (see Suzuki and Chen, 1990). In addition, endothelium-derived contracting factor (EDCF) may also be a factor which influences the active tone by potentiating it.

In the present experiment, mechanisms of the development of the vascular active tone and influences of NO were studied using normotensive Wistar Kyoto rats (WKY) and various strains of genetically hypertensive rats such as spontaneously hypertensive rats (SHR), strokeprone SHR (SHRSP) and malignant SHRSP (M-SHRSP) which have various blood pressure. Possibility of the involvement of EDCF and EDHF in controlling the active tone was also studied.

\section{Methods}

WKY, SHR, SHRSP and M-SHRSP were used in the present study. These rats were originally supplied by Dr. Okamoto (see Okamoto, 1982) and bred successively in our animal facility. They were fed with normal chow (SP, Funabashi, Japan) and tap water at constant temperature of $22^{\circ} \mathrm{C}$ and light-dark cycle of $12 \mathrm{hrs}$. SHR, SHRSP and WKY were sacrificed for experiments at the age of 16 weeks. The age of M-SHRSP used in the experiments was 12 weeks, since after that age they had a high incidence of stroke. Systolic blood pressure of these rats was measured by a tail-cuff method. Prior to the measurement, rats were warmed at $40^{\circ} \mathrm{C}$ for $10 \mathrm{~min}$, so that exact blood pressure could be measured.

They were killed by bleeding from vena cava under anesthesia with ethyl ether. Aorta was excised from thoracic cavity and immersed in a modified Tyrode's solution. The composition of the modified Tyrode's solution was as follows (mM) : $\mathrm{NaCl}, 137 ; \mathrm{KCl}, 5.4 ; \mathrm{CaCl}_{2}, 2.0$; $\mathrm{MgCl}_{2}, 1.0 ; \mathrm{NaHCO}_{3}, 11.9 ; \mathrm{NaH}_{2} \mathrm{PO}_{4}, 0.4$; glucose, 5.6 ; equilibrated with a gas mixture of $95 \% \mathrm{O}_{2}$ and $5 \% \mathrm{CO}_{2}$. K-Tyrode's solution was made by replacing all $\mathrm{NaCl}$ in the modified Tyrode's solution with equimolar $\mathrm{KCl}$, and high-K-Tyrode's solution was made by mixing the modified Tyrode's solution and K-Tyrode's solution to obtain the solution which contains desired $\mathrm{K}^{+}$concentration. Ca-free Tyrode's solution was made by omitting $\mathrm{CaCl}_{2}$ in the modified Tyrode's solution. 
Ring preparations of $1 \mathrm{~mm}$ in width were made in the modified Tyrode's solution after fat and connective tissues were cleaned off. In one third of preparations from each strain, endothelium was removed by rubbing inner surface of the ring preparations with soft rubber piece. Two tungsten wires of $30 \mu \mathrm{m}$ diameter were inserted in the lumen of the ring preparations. The preparations were fixed with one tungsten wire in organ baths of $10 \mathrm{ml}$ volume filled with the modified Tyrode's solution; the other tungsten wire was connected to a forcedisplacement transducer (Shinkoh-minevia, Nagano, Japan), so that the isometric tension changes could be recorded. The temperature of the incubation medium was kept at $37^{\circ} \mathrm{C}$ by circulating the warm water of the same temperature in the outer chamber of the organ bath.

Preparations were equilibrated for $60 \mathrm{~min}$ in the modified Tyrode's solution at basal passive tension of $8 \mathrm{mN}$. The basal tension was adjusted by stretching the preparation in Ca-free Tyrode's solution where no active tone was generated. After the equilibration in the modified Tyrode's solution, the preparations were subjected to the initiation of two successive high-Kinduced contractions of $15 \mathrm{~min}$ duration with $30 \mathrm{~min}$ interval by changing the incubation medium from the modified to high-K Tyrode's solution containing $50 \mathrm{mM} \mathrm{K}^{+}$. This procedure was required to obtain constant values of following experiments and the height of the second contraction was used to normalize the value of the subsequent results.

After the experiments, preparations were completely relaxed by the removal of extracellular $\mathrm{Ca}^{2+}$ or by the application of $10^{-5} \mathrm{M}$ verapamil and $10^{-4} \mathrm{M}$ papaverine, and all tension changes were measured from this relaxed level.

The drugs used in the present experiments were; L-arginine (Sigma, St. Louis, MO, USA), D-arginine (Sigma), $\mathrm{N}^{\mathrm{G}}$-nitro-L-arginine (L-NNA, Sigma), indomethacin (Sigma), apamin (Sigma), charybdotoxin (Sigma), tetraethylammonium (TEA, Wako Chemicals, Osaka, Japan), verapamil hydrochloride (Wako Chemicals), nifedipine (Wako Chemicals) and papaverine hydrochloride (Wako Chemicals).

Obtained values were expressed as mean \pm s.e.mean with the numbers of the preparation in parenthesis. All data were subjected to comparison and analysis by one-way analysis of variance (ANOVA), followed by the Newman-Keul's multiple comparison analysis. $\mathrm{P}$ value less than 0.05 was considered to be significant difference.

\section{Results}

Blood pressure and body weight of the rats

Systolic blood pressure of the rats used in the present experiments were higher in the following order WKY $<$ SHR $<$ SHRSP $<$ M-SHRSP (Fig. 1a). The differences among these strains of the rats were significant.

Body weight of the rats decreased as the blood pressure of the rats increased (Fig. 1b). The differences among these strains of the rats were also significant.

Active tone of aorta in various strains of rats

Endothelium-intact aorta of the spontaneously hypertensive rats (SHR, SHRSP and MSHRSP) exhibited weak but significant spontaneous active tone, which was abolished by the 

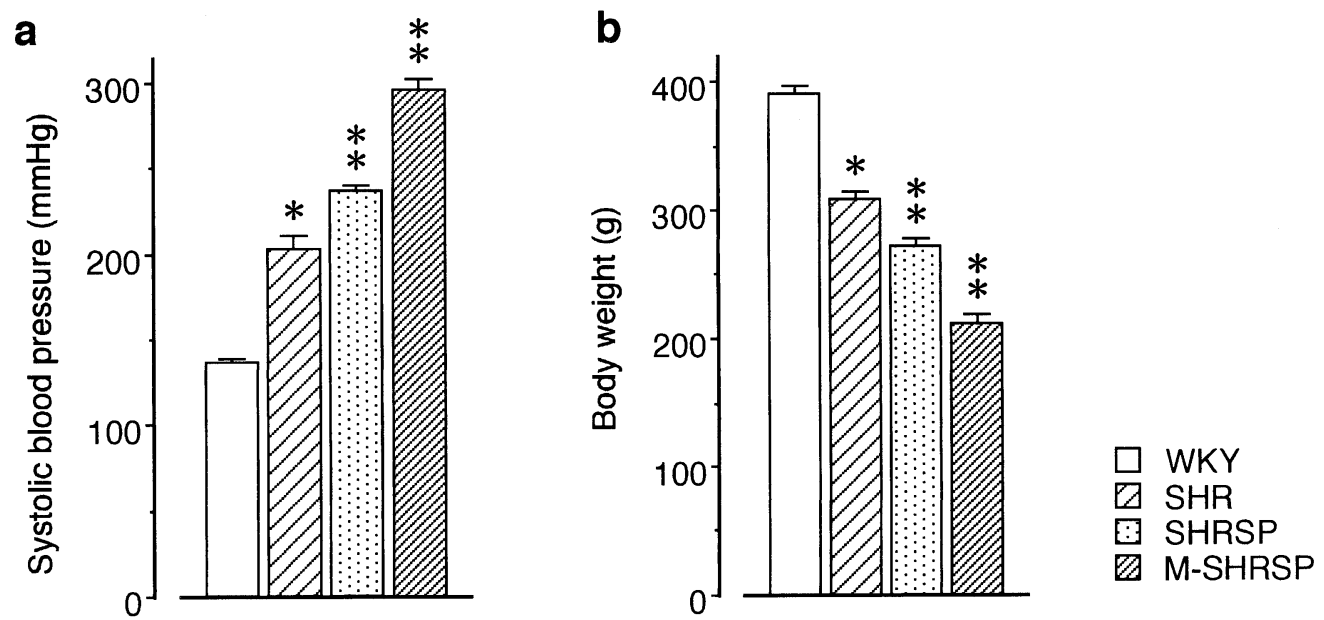

Fig. 1. Systolic blood pressure (a) and body weight (b) of rats. These values were obtained when they were used for the experiments (WKY, SHR and SHRSP : 16-week-old, M-SHRSP : 12-week-old). Asterisks indicate the significant differences between the respective value on WKY $\left({ }^{*}, P<0.05 ;{ }^{* *}, P<0.001\right)$. The values among the various rats were also significant $(P<0.05)$.

removal of extracellular $\mathrm{Ca}^{2+}$ or by the application of nifedipine $\left(10^{-6} \mathrm{M}\right)$ (data not shown). The active tone was greater in the order of the systolic blood pressure of the rats from which the preparations were made. The removal of endothelium markedly potentiated the active tone as reported previously (Sunano et al. 1991; Sunano and Shimamura, 1991).

The effect of $N^{G}$-nitro-L-arginine, L-arginine and D-arginine

In endothelium-intact preparations from SHRSP, the addition of $\mathrm{N}^{\mathrm{G}}$-nitro-L-arginine (LNNA, $10^{-4} \mathrm{M}$ ) caused gradual elevation of the tension, which reached its maximum in 3 to 5 hrs after the application (Fig. 2). The elevation of the tension was prevented by the application of $\mathrm{L}$-arginine of the concentration of $10^{-4} \mathrm{M}$ but not by $\mathrm{D}$-arginine of the concentration up to $10^{-4}$ $\mathrm{M}$ (Figs. 3a and 3b).

Similar slow development of the active tone by L-NNA was observed in the preparations from other hypertensive rats (Fig. 4). The time to peak of the L-NNA-induced tension development was 3 to $5 \mathrm{hrs}$ also in the preparations from the hypertensive rats other than SHRSP. The developed tension increased as the systolic blood pressure of the rats, from

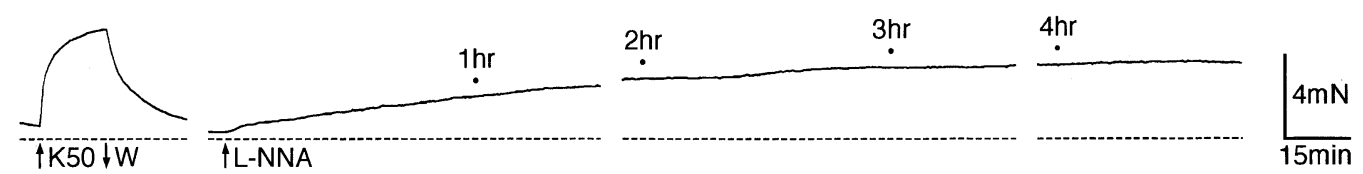

Fig. 2. Time course of the development of the active tone in the preparation from SHRSP after the application of $\mathrm{N}^{\mathrm{G}}$-nitro-L-arginine (L-NNA) of $10^{-4} \mathrm{M}$. The recording was taken continuously for $5 \mathrm{hrs}$ as indicated in the top of the figure. $\mathrm{K} 50$ and $\mathrm{W}$ indicate changing the incubation medium from normal to high- $\mathrm{K}^{+}$Tyrode's solution containing $50 \mathrm{mM} \mathrm{K}^{+}$ and washing out with the normal Tyrode's solution, respectively. Dotted line indicates the base line observed by the removal of extracellular $\mathrm{Ca}^{2+}$. 

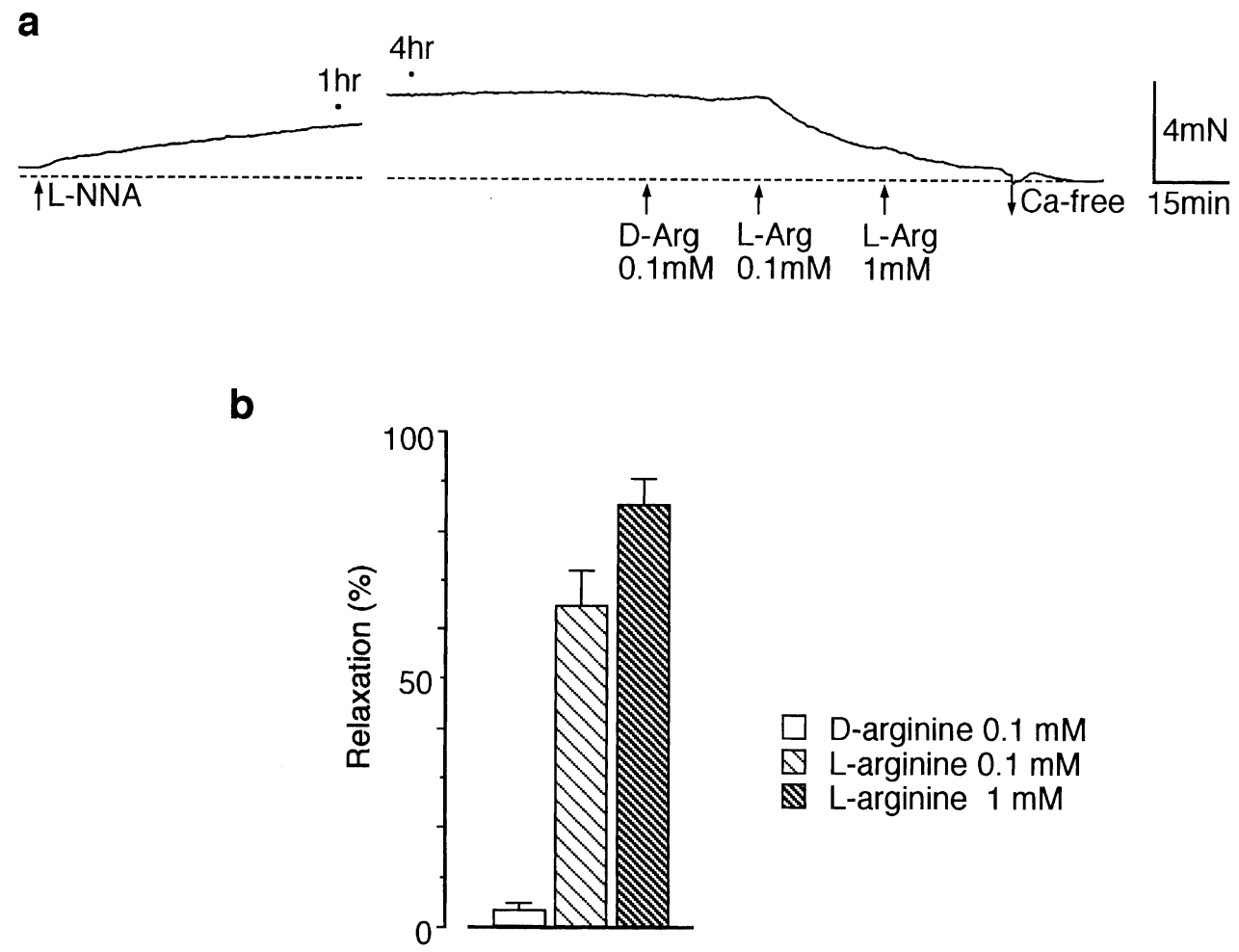

Fig. 3. Depressive effect of $\mathrm{L}$-arginine ( $\mathrm{L}-\arg$ ) on the $\mathrm{N}^{\mathrm{G}}$-nitro-L-arginine (L-NNA)-induced active tone in the preparation from SHRSP. a, the active tone was induced by the application of L-NNA $\left(10^{-4} \mathrm{M}\right)$ and, after $5 \mathrm{hrs}$, D-arginine $(\mathrm{D}$-arg) or $\mathrm{L}$-arginine were added. Dotted line indicates the base line obtained by the removal of extracellular $\mathrm{Ca}^{2+}$. b, depression by L-arginine expressed as percentage of the L-NNA-induced active tone.

which the preparations were made, elevated (Fig. 4 and 5). In addition, it was demonstrated in the present experiments that the developed tension in the presence of L-NNA was greater than those observed in endothelium-denuded preparations (Sasaki et al., 1993).

It was also ascertained that the active tone of endothelium-intact preparations observed in the presence of L-NNA was abolished by the removal of extracellular $\mathrm{Ca}^{2+}$ or the application of verapamil (data not shown).

\section{Involvement of EDCF and endothelium-dependent smooth muscle hyperpolarization}

In the preparations from SHRSP, the application of indomethacin at the concentration of $10^{-6} \mathrm{M}$ and $10^{-5} \mathrm{M}$ depressed the active tone developed in the presence of L-NNA by $15.4 \pm 3.1 \%$ $(n=16)$ and by $25.5 \pm 5.2 \%(n=16)$, respectively (Fig. 6).

Tetraethylammonium (TEA) of the concentration of $10^{-4} \mathrm{M}$ induced gradual tension development (contraction) even in the preparations from WKY. The tension development was often associated with rhythmic oscillation of the tension. The peak of the developed tension was greater than that induced by L-NNA. The tension development by TEA was also 
WKY

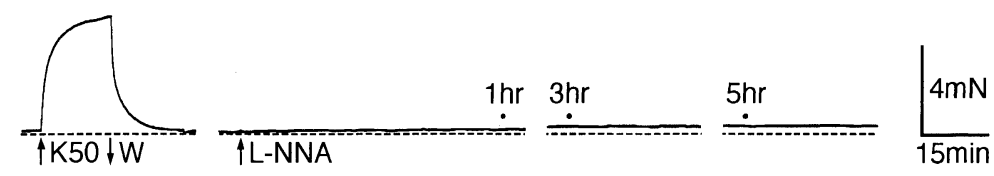

SHR

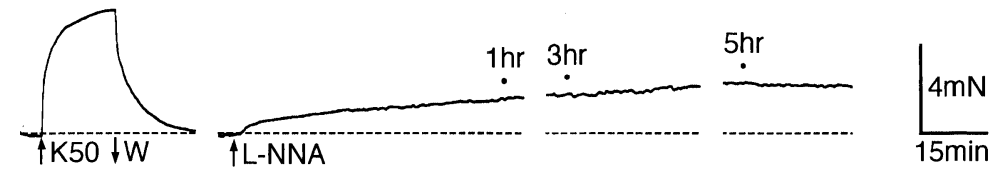

SHRSP
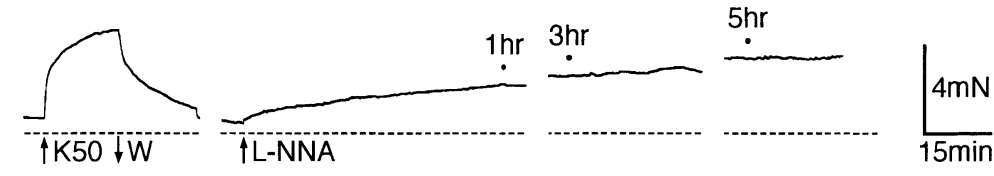

M-SHRSP
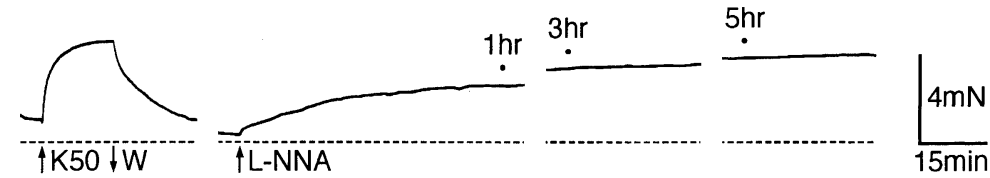

Fig. 4. $\mathrm{N}^{\mathrm{G}}$-nitro-L-arginine (L-NNA)-induced development of the active tone in preparations from various strains of rats. Although the active tone was varied among preparations, it took about 5 hrs to reach its peak in all preparations. Others are the same as those in Fig. 2.
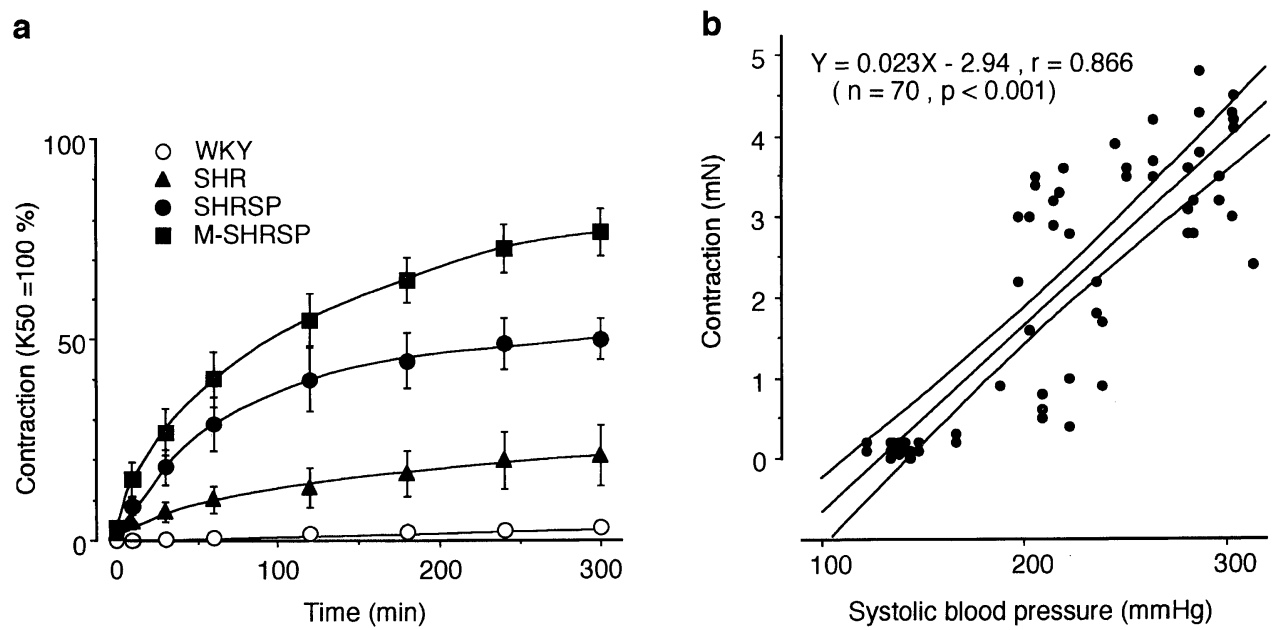

Fig. 5. Time course of the development of the active tone after the application of $\mathrm{N}^{\mathrm{G}}-\mathrm{nitro}-\mathrm{L}-$ arginine (L-NNA, $10^{-4} \mathrm{M}$ ) in the preparation from various strains of rats (a), and relationship between the systolic blood pressure and the active tone (b). In $\mathrm{b}$, the active tone was measured at 5 hrs after the application of L-NNA. Regression line $(\mathrm{Y}=0.023 \mathrm{X}-2.94)$ and range of $95 \%$ reliability are indicated.

observed in endothelium-denuded preparations, and rather greater tension development was induced in these preparations than that in endothelium-intact preparations (data not shown).

Simultaneous application of apamin $\left(10^{-7} \mathrm{M}\right)$ and charybdotoxin $\left(10^{-7} \mathrm{M}\right)$ induced the elevation of the basal tension of endothelium-intact preparations from SHRSP (Fig. 7). The 


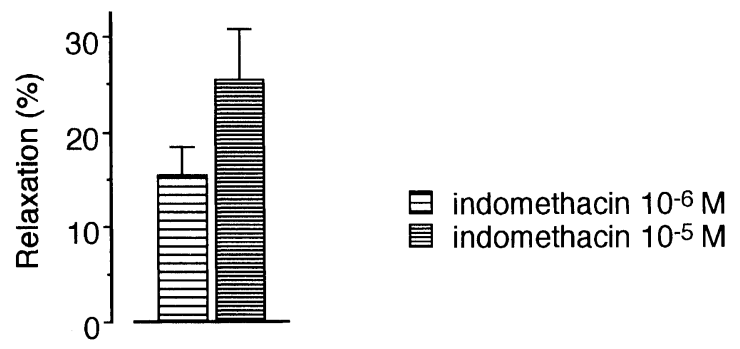

Fig. 6. Depression of the $\mathrm{N}^{\mathrm{G}}$-nitro-L-arginine (L-NNA)-induced active tone by indomethacin. The depression was expressed as percentages of the active tone induced by L-NNA.

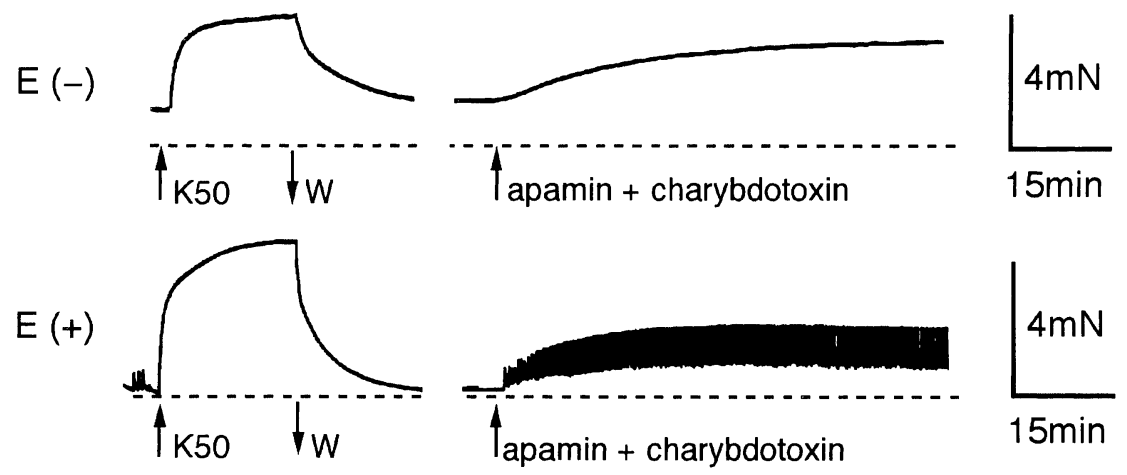

Fig. 7. Effect of treatment with apamin and charybdotoxin on endothelium-intact and-denuded preparations from SHRSP. Apamin $\left(10^{-7} \mathrm{M}\right)$ and charybdotoxin $\left(10^{-7} \mathrm{M}\right)$ were applied simultaneously. Dotted lines indicate the completely relaxed level observed by the application of verapamil $\left(10^{-5} \mathrm{M}\right)$ and papaverine $\left(10^{-4} \mathrm{M}\right)$ as described in the methods. Note the difference in the active tone before the application of the toxins. In the endotheliumintact preparation, the application of toxins often caused the tension oscillation in addition to the elevation of the basal tension.

elevation of the basal tension was often associated with oscillation of tension. The tension development of the similar amplitude was also observed in endothelium-denuded preparations (Fig. 7).

\section{Discussion}

It has been known that the aortic smooth muscle of normotensive rats exhibits no spontaneously developed tension which classified commonly as an active tone or merely tone. The aortic smooth muscles of spontaneously hypertensive rats, however, have the active tone (Noon et al., 1978; Lindner and Heinle, 1987 ; Fitzpatrick and Szentivanyi, 1980 ; Sada et al., 1989 ; Sunano et al., 1992 ; Sasaki et al., 1993 ; Sunano et al., 1996). The active tone of these smooth muscles are sensitive to extracellular $\mathrm{Ca}^{2+}$ and abolished by the removal of $\mathrm{Ca}^{2+}$ from incubation medium or by the application of Ca antagonists (Sunano et al., 1996; Sada et al., 1989; Fitzpatrick and Szentivanyi, 1980 ; Lindner and Heinle, 1987 ; Noon et al., 1978). We have confirmed these in the present experiments with endothelium-denuded preparations. The active tone has been known to be depressed by endothelium (Sunano et al., 1991 ; Sunano and 
Shimamura, 1991). Endothelium-derived relaxing factor, which has been identified as nitric oxide (NO) (Moncada et al., 1988 ; Palmer et al., 1987), may be the first candidate which induces this depression. In the present experiments, the involvement of NO was studied using L-NNA, which has been known to inhibit the synthesis of NO from L-arginine (Moore et al., 1990 ; Ishii et al., 1990 ; Mulsch and Busse, 1990). In addition, the concentration of L-NNA used in the present experiments $\left(10^{-4} \mathrm{M}\right)$ has been known to inhibit the endothelium-dependent relaxation of aortic preparations from both WKY and SHRSP completely (Sekiguchi et al., 1996).

The possibility of the involvement of NO in the depression of the active tone and its relief by L-NNA is supported by the result that the active tone was blocked by L-arginine but not by $\mathrm{D}$-arginine. It is known that $\mathrm{NO}$ is synthesized from $\mathrm{L}$-arginine (Palmer et al., 1988a ; Palmer et al., 1988b) and that D-arginine can not be substituted for L-arginine (Palmer et al., 1988a). In addition, it has also been reported that the inhibition of endothelium-derived NOinduced relaxation was counteracted by $\mathrm{L}$-arginine but not by $\mathrm{D}$-arginine (Moore et al., 1990). Therefore, the development of the active tone by L-NNA indicates that, in endothelium-intact preparations, the active tone of smooth muscle is depressed by endothelium-derived NO and its blockade by L-NNA is the cause of the development of the elevation of basal tension. Spontaneous or basal release of endothelium-derived NO (Martin et al., 1986 ; see Martin, 1988) would continuously be depressing the active tone of smooth muscle.

The present experiments showed that the tension development induced by L-NNA was slow. The active tone of aortic smooth muscle is brought about by influxed $\mathrm{Ca}^{2+}$ through voltage-dependent $\mathrm{Ca}^{2+}$ channels (Sasaki et al., 1993 ; Lindner and Heinle, 1987). Then, the slow development of the active tone by L-NNA may be explained by the slow development of that in the smooth muscle. Indeed, we have observed that the development of the active tone in the endothelium-denuded aortic preparations from SHRSP took about $1 \mathrm{hr}$ (Sunano et al., 1992). However, the time to peak of the L-NNA-induced active tone was 3 to $5 \mathrm{hrs}$ which was longer than that observed in the endothelium-denuded preparations. It is unlikely that the slowness of the inhibition of NO synthase by L-NNA contributes to the slow development of the active tone, since it has been reported that the incubation with L-NNA for 10 min is enough to inhibit NO synthase activity in the porcine aortic endothelial cells (Mayer et al., 1993). Further research is required to clarify the slow development of the active tone by L-NNA.

We have observed that the application of high concentration of acetylcholine induced endothelium-dependent contraction of aorta from SHRSP but not that from WKY in the presence of L-NNA (Shimamura et al., unpublished observation). This suggests the possibility of the involvement of EDCF in the modification of endothelium-dependent relaxation, and, through this, in the development of the active tone by L-NNA. The EDCF, that is involved in the contraction or the impairment of endothelium-dependent relaxation in SHRSP preparations, has been elucidated to be a product of arachidonic acid cascade through cyclooxygenase pathway (Lüscher and Vanhoutte, 1986 ; Kato et al., 1990 ; Ito et al., 1991). It has also been reported that NO inactivates EDCF (Auch-Schwelk et al.,1992), and that NO is a modulator of arachidonic acid cascade (Kanner et al., 1992). These results suggest that the inhibition of NO production may bring about the increase in EDCF, and thus may induce active tone or potentiate it. In fact, an activation of cyclooxygenase by $\mathrm{N}^{\mathrm{G}}$-monomethyl-L-arginine ( $\mathrm{L}-$ 
NMMA), which has similar action to L-NNA on NO synthesis, has been proposed in brain microcirculation (Rosenblum et al., 1992).

It was demonstrated in the present experiments that treatment with indomethacin depressed the active tone. Indomethacin has been known to inhibit cyclooxygenase pathway of arachidonic acid cascade (Mizuno et al., 1982 ; see Flower, 1974) and the result, therefore, indicates the possibility of involvement of EDCF in modifying the active tone. However, the active tone of aorta from spontaneously hypertensive rats was also observed in endotheliumdenuded preparations, although its amplitude was slightly reduced, indicating that the active tone can be initiated without involvement of EDCF.

It is possible that the active tone of smooth muscle, which is induced by $\mathrm{Ca}^{2+}$ influx through voltage-dependent $\mathrm{Ca}^{2+}$ channels, is depressed by the hyperpolarization of smooth muscle membrane (see Nelson et al., 1990 ; Garland et al., 1995). The possibility of basal release of EDHF has been reported in certain blood vessels (Beny and Brunet, 1988 ; see also Garland et $a l .$, 1995). In addition, it has also been reported that L-NNA induced depolarization of aortic smooth muscle membrane and increased ${ }^{45} \mathrm{Ca}$ uptake, which was blocked by $\mathrm{Ca}$ antagonists (Krippeit-Drews et al., 1992). However, it was shown in the present experiments that no contraction was initiated in the preparations from WKY by L-NNA, indicating that the depolarization enough to initiate contraction would not be induced by L-NNA.

The possibility of the involvement of EDHF, which is distinct from NO, in the depression of the active tone of aorta can be excluded, since the treatment with L-NNA could initiate the active tone of the rather higher amplitude compared with that observed in endotheliumdenuded preparations. In addition, we have observed that the endothelium-dependent relaxation of aorta is completely blocked by L-NNA as described above (Sekiguchi et al., 1996), suggesting that the depressing effect is mainly mediated by endothelium-derived NO. In support of this, it has been reported that the hyperpolarization by EDHF is smaller in the preparations from aorta when compared with those from smaller arteries (Shimokawa et al., 1996).

It is also possible that the membrane of the smooth muscle of the preparations from SHRSP is less negative enough to induce contraction and the spontaneous release of NO hyperpolarizes this membrane beyond the level for contraction. The blockage of NO production causes an inhibition of this hyperpolarization. However, experiments with agents which blocks membrane hyperpolarization could not be successfully performed, since these agents themselves induced contraction even in the endothelium-denuded preparations or the preparations from WKY. Further studies are required to elucidate the involvement of membrane potential change in the development of the active tone due to the application of L-NNA.

In conclusion, the endothelium-dependent depression of the active tone in aortic preparations from spontaneously hypertensive rats is brought about by endothelium-derived NO. The active tone is originated from aortic smooth muscle and EDCF has potentiating effect on the developed active tone, although it has no role in producing the active tone. EDHF has minor role in controlling the active tone in the aorta of spontaneously hypertensive rats. 


\section{References}

Auch-Schwelk, W., Katusic, Z.S. and Vanhoutte, P.M. (1992). Nitric oxide inactivates endotheliumderived contracting factor in the rat aorta. Hypertension 19: 442-445.

Beny, J.-L. and Brunet, P.C. (1988). Electrophysiological and mechanical effects of substance P and acetylcholine on rabbit aorta. J. Physiol. 398: 277-289.

Fitzpatrick, D.F. and Szentivanyi, A. (1980). The relationship between increased myogenic tone and hyporesponsiveness in vascular smooth muscle of spontaneously hypertensive rats. Clin. Exp. Hypertension 2: 1023-1037.

Flower, R.J. (1974). Drugs which inhibit prostaglandin biosynthesis. Pharmacol. Rev. 26: 33-67.

Garland, C.J., Plane, F., Kemp, B.K. and Cooks, T.M. (1995). Endothelium-dependent hyperpolarization: a role in the control of vascular tone. TiPS $16: 23-30$.

Ishii, K., Chang, B., Kerwin, J.F. Jr., Huang, Z.-J. and Murad, F. (1990). $\mathrm{N}^{\omega}$-nitroarginine : a potent inhibitor of endothelium-derived relaxing factor formation. Eur. J. Pharmacol. 176: 219223.

Ito, T., Kato, T., Iwama, Y., Muramatsu, M., Shimizu, K., Asano, H., Okumura, K., Hashimoto, H. and Satake, T. (1991). Prostaglandin $\mathrm{H}_{2}$ as an endothelium-derived contracting factor and its interaction with endothelium-derived nitric oxide. J. Hypertension 9: 729-736.

Kanner, J., Harel, S. and Granit, R. (1992). Nitric oxide, an inhibitor of lipid oxidation by lipoxygenase, cyclooxygenase and hemoglobin. Lipids $27: 46-49$.

Kato, T., Iwama, Y., Okumura, K., Hashimoto, H., Ito, T. and Satake, T. (1990). Prostaglandin $\mathrm{H}_{2}$ may be the endothelium-derived contracting factor released by acetylcholine in the aorta of the rat. Hypertension 15: 475-481.

Krippeit-Drews, P., Morel, N. and Godfraind, T. (1992). Effect of nitric oxide on membrane potential and contraction of rat aorta. J. Cardiovasc. Pharmacol. 20(Suppl. 12) : S72-S75.

Lindner, V. and Heinle, H. (1987). $\mathrm{Ca}^{2+}$ influx in spontaneously hypertensive rats is sensitive to calcium antagonists. Eur. J. Pharmacol. 138: 147-149.

Lüshcer, T.F. and Vanhoutte, P.M. (1986). Endothelium-dependent contraction to acetylcholine in the aorta of the spontaneously hypertensive rat. Hypertension $8: 344-348$.

Martin, W. (1988). Basal release of endothelium-derived relaxing factor. In: Relaxing and contracting factors, ed. by P.M. Vanhoutte, Humana Press, Clifton NJ, pp. 159-178.

Martin, W., Furchgott., Villani, G.A. and Jothianandan, D. (1986). Depression of contractile responses in rat aorta by spontaneously released endothelium-derived relaxing factor. $J$. Pharmacol. Exp. Ther. 237: 529-538.

Mayer, B., Schmid, M., Klatt, P. and Schmidt, K. (1993). Reversible inactivation of endothelial nitric oxide synthase by $\mathrm{N}^{\mathrm{G}}$-nitro-L-arginine. FEBS Letters, 333 : 203-206.

Mizuno, K., Yamamoto, S. and Lands, W.E.M. (1982). Effects of nonsteroidal anti-inflammatory drugs on fatty acid cyclooxygenase and prostaglandin hydroperoxidase activities. Prostaglandins 23 : 743-757.

Moncada, S., Palmer, R.M.J. and Higgs, E.A. (1989). Biosynthesis of nitric oxide from L-arginine. a pathway for the regulation of cell function and communication. Biochem. Pharmacol. 38: 1709-1715.

Moncada, S., Radomski, M.W. and Palmer, R.M.J. (1988). Endothelium-derived relaxing factor. Identification as nitric oxide and role in the control of vascular tone and platelet function. Biochem. Pharmacol. 37 : 2495-2501.

Moore, P.K., al-Swayeh, O.A., Chong, N.W.S., Evans, R.A. and Gibson, A. (1990). L-N $\mathrm{N}^{\mathrm{G}}$-nitroarginine (L-NOARG), a novel, L-arginine-reversible inhibitor of endothelium dependent vasodilatation in vitro. Br. J. Pharmacol. $99: 408-412$.

Mulsch, A. and Busse, R. (1990). $\mathrm{N}^{\mathrm{G}}$-nitro-L-arginine (N5-[imino(nitroamino)methyl]-L-ornitine) 
impairs endothelium-dependent dilations by inhibiting cytosolic nitric oxide synthesis from L-arginine. Naunyn-Schmiedeberg's Arch. Pharmacol. 341 : 143-147.

Nelson, M.T., Patrak, J.B., Worley, J.F. and Standen, B. (1990). Calcium channels, potassium channels and voltage dependence of arterial smooth muscle tone. Am. J. Physiol. 259 : C3C18.

Noon, J.P., Rice, P.J. and Baldessarini, R.J. (1978). Calcium leakage as a cause of the high resting tension in vascular smooth muscle from the spontaneously hypertensive rat. Proc. Natl. Acad. Sci. USA 75 : 1605-1607.

Okamoto, K. (1982). Developing an animal model for hypertension and utilizing in research. Medicina Philosophica 1: 459-474 (in Japanese).

Palmer, R.M.J., Ashton, D.S. and Moncada, S. (1988a). Vascular endothelial cells synthesize nitric oxide from L-arginine. Nature 333 : 664-666.

Palmer, R.M.J., Ferrige, A.G. and Moncada, S. (1987). Nitric oxide release account for the biological activity of endothelium-derived relaxing factor. Nature 337 : 524-526.

Palmer, R.M.J., Ress, D.D. and Ashton, D.S. (1988b). L-arginine is the physiological precursor for the formation of nitric oxide in endothelium-dependent relaxation. Biochem. Biophys. Res. Commun. 153 : 1251-1256.

Rosenblum, W.A., Nishimura, H. and Nelson, G.H. (1992). L-NMMA in brain microcirculation of mice is inhibited by blockade of cyclooxygenase and by superoxide dismutase. Am. J. Physiol. 262 : H1343-H1349.

Sada, T., Koike, H. and Miyamoto, M. (1989). Long-term inhibition of angiotensin converting enzyme suppress calcium channel agonist-induced contraction of aorta in hypertensive rat. Hypertension 14 : 652-659.

Sasaki, F., Osugi, S., Shimamura, K. and Sunano, S. (1993). Relationship between blood pressure and smooth muscle tone in aortae of hypertensive rats: role of $\left[\mathrm{Ca}^{2+}\right] . J$. Smooth Muscle Res. 29 : 69-79.

Sekiguchi, F., Adachi, T., Matsubara, H., Matsuda, K., Kita, K., Shimamura, K. and Sunano, S. (1996). Spontaneous and agonist-induced contractions and endothelium-dependent relaxation in aortae from SHRSP and WKY rats under various levels of passive force. Clin. Exper. Pharmacol. and Physiol. 23: 483-489.

Shimokawa, H., Yasutake, H., Fujii, K., Owada, M.K., Nakaike, R., Fukumoto, Y., Takayanagi, T., Nagao, T., Egashira, K., Fujishima, M. and Takeshita, A. (1996). The importance of the hyperpolarizing mechanism increases as the vessel size decreases in endothelium-dependent relaxations in rat mesenteric circulation. J. Cardiovasc. Pharmacol. 28: 703-711.

Sunano, S., Osugi, S., Kaneko, K., Yamamoto, K. and Shimamura, K. (1992). Effects of chronic treatment with SQ29852 on spontaneous smooth muscle tone and endothelium-dependent relaxation in aorta of stroke-prone spontaneously hypertensive rats. J. Cardiovasc. Pharmacol. 19 : 602-609.

Sunano, S., Osugi, S., Yamamoto, K. and Shimamura, K. (1991). Influence of the endothelium on the elevation of basal tension in aortae from various strains of spontaneously hypertensive rats. J. Cardiovasc. Pharmacol. 17(Suppl. 3) : S137-S140.

Sunano, S., Sekiguchi, F., Takeuchi, K., Shibutani, S., Matsuda, K. and Shimamura, K. (1996). Attenuation of intrinsic active tone by endothelium-derived nitric oxide in aortae of spontaneously hypertensive rats with different levels of blood pressure. Clin. Exper. Hypertension 18: $873-890$.

Sunano, S. and Shimamura, K. (1991). Smooth muscle tone of aorta of spontaneously hypertensive rats due to an increase in the voltage-dependent $\mathrm{Ca}$ channel and its modification by endothelium. In: Ion channels of vascular smooth muscle cells and endothelial cells, ed. by N. Speralakis and H. Kuriyama, Elsevier, New York, pp. 225-233. 
Suzuki, H. and Chen, G. (1990). Endothelium-derived hyperpolarizing factor: an endogenous potassium-channel activator. News Physiol. Sci. 5: 212-215.

(Received December 7, 1998 : Accepted February 9, 1999) 